\title{
Feedback Survey on the Usability of the OFFERA Method for Assessing an Exposure Risks of Computer Work Related to WMSDs
}

\author{
Mohd Nasrull Abdol Rahman*, Siti Shafika Mohamad, Salihatun Md Salleh, Shahruddin \\ Mahzan and Sufizar Ahmad \\ Department of Manufacturing and Industrial Engineering Faculty of Mechanical and Manufacturing \\ Engineering, Universiti Tun Hussein Onn Malaysia (UTHM), 86400 Parit Raja, Batu Pahat, Johor, \\ Malaysia
}

\begin{abstract}
The OFFERA method was designed to assess the exposure of the office workstation risk factors associated with WMSDs. This method involved six domains which include chair, desk, input device, monitor, accessories, and the environment. The purpose of this study was to assess the usability of the OFFERA method for assessing exposure risks of computer work related to WMSDs. The participants were trained to conduct the OFFERA method. Trial assessments on three different office jobs were conducted. The usability of the OFFERA method was identified based on the feedback questionnaire survey obtained from 44 practitioners (undergraduate students) after the training. From the usability test, the OFFERA method was found be easy to use (mean $4.48 \pm 0.698$ ) and quick to use (mean $4.48 \pm 0.821$ ). However, the observers found that the font used was too small hence it was difficult to read the instruction (mean 3.93 $\pm 1.096)$. The pictures or illustrations in the OFFERA tool were also recorded as unclear based on the relatively low score for 18 items (mean $3.73 \pm 1.128$ ). Besides that, all participants agreed that OFFERA method is user-friendly, cost effective and applicable to a wide range of office-related activities.
\end{abstract}

\section{Introduction}

Work-related musculoskeletal disorders (WMSDs) common health problems related to work. [1-2]. Besides the lower-back region, the neck and upper extremities are the most affected regions for industries such as construction, mould manufacturing, car service centre, and occupational computer use [2-5]. Some of the risk factors associated with MSDs among of the computer users are maintaining a static sitting posture for a long time, awkward posture of the head, neck and upper limb, wrist, and forearm and repetitive movement of the fingers [5-10]. There are a variety of methods which have been developed to assess posture in order to assess risk factors for WMSDS. An ergonomic risk assessment tool is the one of the methods that can be used [11]. Seven ergonomic risk assessment tools

\footnotetext{
*Corresponding author: mnasrull@uthm.edu.my
} 
which have been widely used for WMSDs related to office workstations include Rapid Upper Limb Assessment [12], Rapid Entire Body Assessment [13], Computer Workstation e-Tool [14], Quick Exposure Checklist [15], Assessment of Repetitive Task [16], Office Ergonomic Assessment [6], and Rapid Office Strain Assessment [5]. The Office Ergonomic Risk Assessment (OFFERA) method was developed to assess the exposure of office risk factors associated with work-related musculoskeletal disorders (WMSDs). This method involves the assessment of office components (chairs, desks, input devices, monitors, and accessories) and the office environment. The usability test is a method that shows the strengths and weakness in the usability of the tool or system for a measure of comparing the usability [17]. However, most of the eligible tools were not tested in terms of the usability [12-14]. Therefore, this study was carried out to assess the usability of the OFFERA method for assessing the exposure risk of computer work related to WMSDs.

\section{Method}

\subsection{Study design}

Forty-four mechanical and manufacturing engineering undergraduates' students were involved in a workshop conducted in Universiti Tun Hussein Onn Malaysia (UTHM), Johor. This training session was conducted by the researchers. All the participants who had undertaken risk assessment were trained to conduct the OFFERA method. This involved a trial assessment of three jobs (admin counter, accountant, and research assistant) captured in videos to familiarise the participants with the OFFERA process. After the training session (intra-observer reliability) the participant assesses the usability of OFFERA method based on the three jobs via questionnaire survey which took 30 minutes to complete.

\subsection{Data Collection}

The usability of the OFFERA assessment was assessed using feedback questionnaires survey after the participants had completed the prototype assessment for three jobs during a training session (intra-observer reliability test). The survey consisted of 13 question items about OFFERA (prototype) assessment which include; 1) easy to use and straightforward, 2) quick to use, 3) instruction is clearly to read and understand, 4) wording is clearly to read and understand, 5) pictures/illustrations is clearly to see and understand, 6) scoring system is easy to interpret the results, 7) score for each item is easy to understand, 8) final score is easy to understand, 9) action level is easy to understand, 10) applicable to workplace assessment, 11) applicable to wide range of job/tasks, 12) valuable to works (cost effective), and 13) valuable at works (provide a good basis for intervention proposal). The survey consisted of close-ended questionnaire that used the five points of the Likert Scale rating $(1=$ strongly disagree, $5=$ strongly agree). The questionnaire survey also included demographic items such as the subject's age, gender, and education level. Besides that, the survey consisted of general comments and suggestions for part B whereas Part C consisted of specific comment and suggestion for each item. The completed prototype assessment and feedback questionnaires were collected and stored securely. Data from the prototype tool and feedback questionnaires were analysed using Microsoft Excel 2007. 


\subsection{Data Analysis}

The usability of the OFFERA tool was assessed using descriptive statistics. The mean (X) and standard deviation (SD) were used to evaluate and analyse each item of the questionnaire answered by all participants $(\mathrm{N}=44)$. Statistical analysis was performed using Statistical Package for Social Sciences (SPSS) software Version 20 and Microsoft Office Excel (Version 2007).

\section{Results}

\subsection{Feedback Survey for Usability of the OFFERA method}

The results from the feedback surveys used to assess the usability of the OFFERA method are shown in Table 1 and Figure 1. All observers' $(N=44)$ rating (1= strongly disagree, $5=$ strongly agree) indicated that the prototype of the OFFERA method was easy to use and straightforward (mean $4.48 \pm 0.698$ ), quick to use (mean $4.48 \pm 0.821$ ), instruction is clearly to read and understand (mean $3.93 \pm 1.149$ ), wording is clearly to read and understand (mean $3.93 \pm 1.096$ ), pictures / illustrations which are clearly to see and easy to understand (mean $3.73 \pm 1.128$ ), scoring system is easy to see and understand (mean $4.59 \pm 0.622$ ), score for each item is easy to understand (mean $4.50 \pm 0.792$ ), final score is easy to understand (mean $4.68 \pm 0.639$ ), action level is easy to understand (mean $4.52 \pm$ 0.549 ), applicable to workplace assessment (mean $4.52 \pm 0.549$ ), applicable to wide range of job / tasks (mean $4.02 \pm 0.952$ ), cost effective (mean $4.36 \pm 0.685$ ), and provide a good basis for intervention proposal (mean $4.41 \pm 0.583$ ).

Table 1. Feedback Survey on the usability of the OFFERA method

\begin{tabular}{|c|l|c|c|c|c|c|c|}
\hline \multirow{2}{*}{ No } & \multicolumn{1}{|c|}{ Questions } & \multicolumn{5}{|c|}{ Rating Score } & Total score \\
\cline { 3 - 9 } & & $\mathbf{1}$ & $\mathbf{2}$ & $\mathbf{3}$ & $\mathbf{4}$ & $\mathbf{5}$ & Mean (SD) \\
\hline 1 & Easy to use and straightforward & 1 & - & 2 & 16 & 25 & $4.48(0.698)$ \\
\hline 2 & Quick to use & 1 & - & 3 & 14 & 26 & $4.48(0.731)$ \\
\hline 3 & $\begin{array}{l}\text { Instruction is clearly to read and } \\
\text { understand }\end{array}$ & 2 & 4 & 6 & 15 & 17 & $3.93(1.149)$ \\
\hline 4 & $\begin{array}{l}\text { Wording is clearly to read and } \\
\text { understand }\end{array}$ & 2 & 3 & 7 & 17 & 15 & $3.91(1.096)$ \\
\hline 5 & $\begin{array}{l}\text { Pictures / Illustrations is clearly to see } \\
\text { and understand }\end{array}$ & 2 & 5 & 8 & 17 & 12 & $3.73(1.128)$ \\
\hline 6 & $\begin{array}{l}\text { Scoring system is easy to see and } \\
\text { understand }\end{array}$ & - & - & 3 & 12 & 29 & $4.59(0.622)$ \\
\hline 7 & $\begin{array}{l}\text { Score for each items is easy to } \\
\text { understand }\end{array}$ & 1 & - & 2 & 14 & 27 & $4.50(0.792)$ \\
\hline 8 & Final score is easy to understand & 1 & - & 1 & 9 & 33 & $4.68(0.639)$ \\
\hline 9 & Action level is easy to understand & - & - & 1 & 19 & 24 & $4.52(0.549)$ \\
\hline 10 & Applicable to workplace assessment & - & - & 1 & 19 & 24 & $4.52(0.549)$ \\
\hline 11 & Applicable to wide range of job / tasks & 2 & - & 7 & 21 & 14 & $4.02(0.952)$ \\
\hline 12 & Valuable to works (cost effective) & - & - & 5 & 18 & 21 & $4.36(0.685)$ \\
\hline 13 & $\begin{array}{l}\text { Valuable at works (provide a good basis } \\
\text { for intervention proposal) }\end{array}$ & - & - & 2 & 22 & 20 & $4.41(0.583)$ \\
\hline
\end{tabular}

Notes: rating scale range from $1=$ strongly disagree to $5=$ strongly agree 
Figure 1 shows the results in terms of percentage on the feedback survey of usability of the OFFERA method by 44 observers (undergraduate's student). All of the observers strongly agree and agree that the prototype of the OFFERA method was easy to use and straightforward (93\%), quick to use (91\%), has a clear instructions and easy to understand (73\%), clear wording and easy to understand (73\%), clear pictures/illustrations which are easy to understand (66\%), scoring system is easy to see and understand $(93 \%)$, score for each item is easy to understand (93\%), final score which is easy to understand $(95 \%)$, action levels which are easy to understand (98\%), applicable to workplace assessment (98\%) applicable to a wide range of job/tasks (80\%), cost effective (89\%), and provide a good basis for intervention proposal (95\%). From the results, more than $60 \%$ of the observers agree and strongly agree with the questionnaire items.

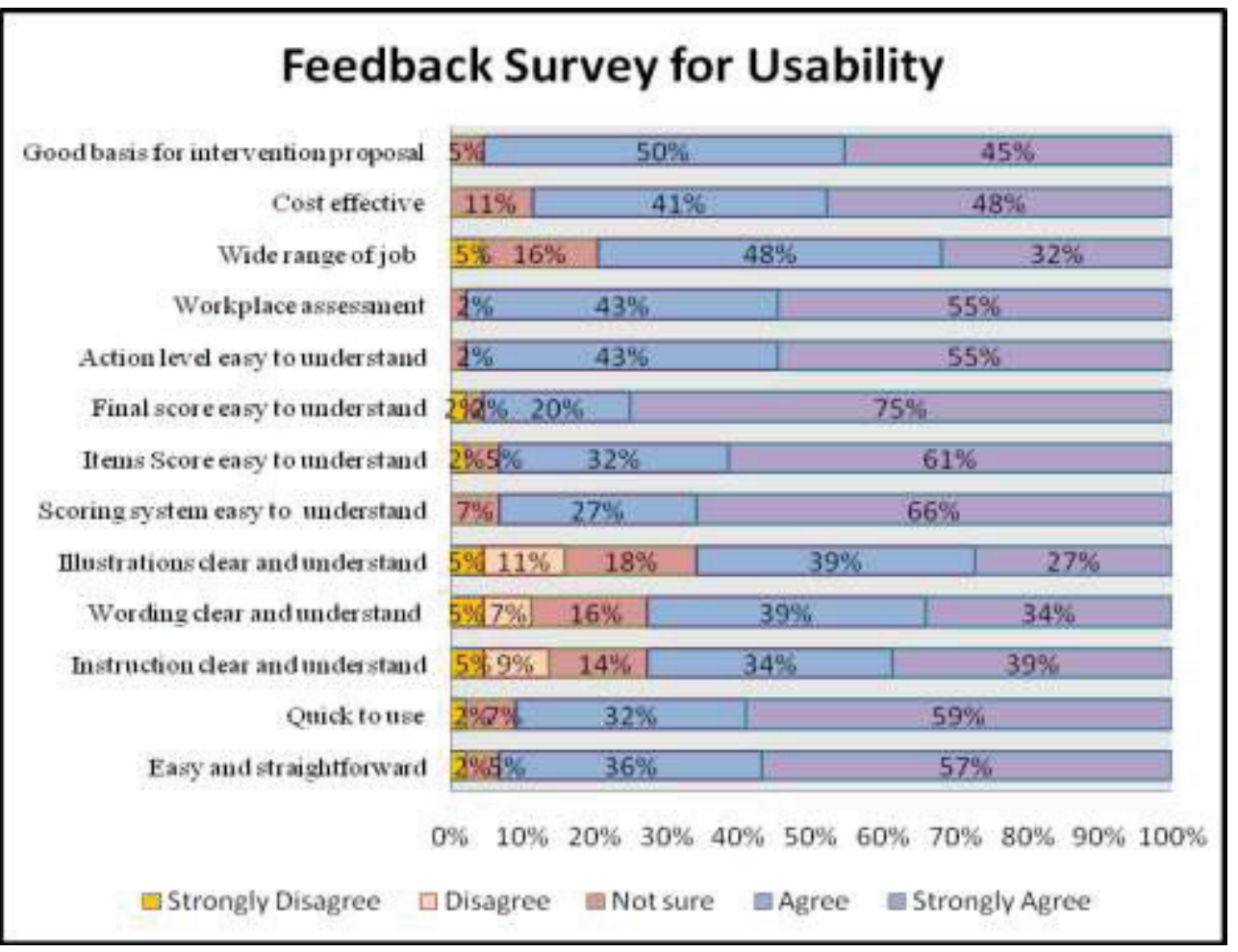

Fig 1. Feedback Survey on the usability of the OFFERA method

\subsection{General comments and suggestions for the OFFERA method}

All of the participants gave their general comments and suggestions on the OFFERA method. Table 2 shows the summary of feedback given by the observers. The observers commented that the assessment tool was very good for assessing ergonomic risks (good for ergonomic users) and that the tool was very useful as it can be used for a wide range of office work (useful for assessing the workplace environment). This is because the assessment tool was easy to use and understand (easy to judge). However, some of the observers commented that the tool was too difficult to read because the font used was too small. The observers also found the tool confusing and difficult to assess when the instructions on how to use the assessment were not provided especially when at the part where more than one action have shown, hence the final sub score is a combination of two 
actions. Observers also commented that the section about environment part, they state the range of the environment especially for lighting and noise was not flexible enough.

Table 2. Feedback Comments from observer

\begin{tabular}{|c|l|}
\hline No & \multicolumn{1}{|c|}{ Comment } \\
\hline 1 & Very good tool to access the ergonomic risk (good for ergonomic users) \\
\hline 2 & Easy to understand and easy to use (easy to judge) \\
\hline 3 & $\begin{array}{l}\text { This OFFERA Tool is a good to ensure the person always in good posture that can be avoid } \\
\text { from hazard }\end{array}$ \\
\hline 4 & Suitable for learning session because it easy to understand \\
\hline 5 & $\begin{array}{l}\text { OFFERA tool is very useful to office workers survey and can be used for all range of office } \\
\text { works (useful to access workplace environment). }\end{array}$ \\
\hline 6 & Easy to get final score and make the action based on final score \\
\hline 7 & Font of the tool too small - difficult to read \\
\hline 8 & For mouse positioned, put box left and right make it more confusing \\
\hline 9 & C1 and E1 make a confused because need give the score for two part \\
\hline 10 & Range for environment part especially for lighting and noise not enough \\
\hline 11 & $\begin{array}{l}\text { For some part, more than one action is shown; hence the final sub score is combination of } \\
\text { two action. Make it confused because not provided instruction how to use this assessment }\end{array}$ \\
\hline 12 & $\begin{array}{l}\text { The probability for employees to work more than 4-5 hours a day is high because it } \\
\text { multiplication }\end{array}$ \\
\hline 13 & Use of colour and illustration/ diagram not clear and hard to understand. \\
\hline
\end{tabular}

In addition, Table 3 shows a summary of the suggestions from practitioners. Most of the practitioners found the wording or font of the sentences too small making them difficult to read. Other than that, the observers also suggested that the illustrations and the dimension for each diagram should be enlarged to make them clearer and more understandable. When the wordings, illustration, and dimension clear, it easier to observer access the level of office workers risks using this tool. The observers suggested enlarging the font size of the sentences. Observers suggested putting one box if the item only for one user. An example mouse positioned which are only uses one side either left or right hand to clicking the mouse. The rigid range of the section on the environment part made it difficult for the observers to assess. Therefore, improvement needs to make by adding a wider range for lighting and noise.

Table 3. General comments and suggestions from the observers

\begin{tabular}{|c|l|}
\hline No & \multicolumn{1}{c|}{ Suggestions / recommendations } \\
\hline 1 & Wording need to be clear and enlarge the font \\
\hline 2 & If only one user, no need put box left and right, just put one box only. \\
\hline 3 & Need to bold the keyword, C1 and E1 need have distance \\
\hline 4 & $\begin{array}{l}\text { Need improvement for office environment part with added more range for lighting and } \\
\text { noise }\end{array}$ \\
\hline 5 & Suggested a simple instruction should be provided before proceed \\
\hline 6 & Adjust work hours are more suited to the actual working time for Step 7 \\
\hline 7 & $\begin{array}{l}\text { Use basic colour or contrast between one section ratings. Enlarge the diagram and } \\
\text { dimension to make it more clear and understandable. }\end{array}$ \\
\hline
\end{tabular}




\subsection{Specific comments and suggestions for the OFFERA method}

In this section, the comments and suggestions from 44 observers for each part of the OFFERA Method which consisted of six part of risk factors which include Part A (chair), Part B (desk), Part C (device input), Part D (monitor), Part E (accessories), and Part F (environment) are presented. Table 4 shows the summary of the specific comments and suggestions for all of the risk factors items.

Table 4. Comments and suggestions for Part A, B, C, D, E, and F

\begin{tabular}{|c|c|c|}
\hline Items & Comments & Suggestions \\
\hline $\begin{array}{l}\text { Part A: Chair Risk } \\
\text { Factor } \\
\text { A1 - Seat Pan } \\
\text { Height } \\
\text { A2 - Seat Pan } \\
\text { Depth } \\
\text { A3 - Backrest } \\
\text { A4 - Armrest }\end{array}$ & $\begin{array}{l}\text { - Dimension for item A2 not cleared } \\
\text { - Dimension too small } \\
\text { - Clear and interesting } \\
\text { - For A4 section- how do you } \\
\text { differentiate between the hands } \\
\text { placed on a desk with a chair } \\
\text { - Using "OR" word in each } \\
\text { evaluation make confused } \\
\text { - Item A2 not valid (is it sure A2 } \\
\text { effect ergonomic). } \\
\text { - Need considered leg position for } \\
\text { both side } \\
\text { - Have armrest but not used. The } \\
\text { risk is high } \\
\text { - Font too small } \\
\text { - No rating for comfort seat } \\
\text { - Too many words } \\
\text { - Seat pan height - if legs sticking } \\
\text { behind what score rating } \\
\text { - A1 - at third illustration it } \\
\text { confusing }\end{array}$ & $\begin{array}{l}\text { - Make dimension more bigger and } \\
\text { clear } \\
\text { - Bold the keyword } \\
\text { - Make another diagram which } \\
\text { shows the conditions laid hands } \\
\text { on the table } \\
\text { - Range no of seat pan depth } \\
\text { - Make the diagram clear } \\
\text { - Make separation for hand / leg } \\
\text { for right and left } \\
\text { - Added types of chair (span type } \\
\text { or not) for rating comfort seat } \\
\text { - Have armrest but not used - must } \\
\text { put the high score. } \\
\text { - Change the font size } \\
\text { - Use simple words to explain } \\
\text { - Fix the illustration - Al }\end{array}$ \\
\hline $\begin{array}{l}\text { Part B :Desk Risk } \\
\text { Factor } \\
\text { B1 - Desk Height } \\
\text { B2 - Desk Depth }\end{array}$ & $\begin{array}{l}\text { - Illustration for item B2 confusing / } \\
\text { not clear } \\
\text { - Font and box small } \\
\text { - Instruction not clear } \\
\text { - Keyword for that sentence not } \\
\text { clear } \\
\text { - Desk depth difficult to understand / } \\
\text { to assess } \\
\text { - B2- more bigger desk, more } \\
\text { comfortable } \\
\text { - Need more detail for item B2 } \\
\text { - B1 - not understand for sizing } \\
\text { (confused because don't have } \\
\text { maximum height) } \\
\text { - B2 - illustration for second and } \\
\text { third are confusing }\end{array}$ & $\begin{array}{l}\text { - Can put range } \\
\text { - Change the fornt size (enlarge) } \\
\text { - Bold the keyword } \\
\text { - Added range / score for }>720 \mathrm{~mm} \\
\text { (too high) } \\
\text { - Put more range for desk wide } \\
\text { - Repaired B2 rating } \\
\text { - Make range for a few sizing - B2 } \\
\text { - Perhaps the dimension for B2 in } \\
\text { range and be helpful (clear to } \\
\text { understand for evaluation) } \\
\text { - Try too add symbol > for easy to } \\
\text { understand - B2 }\end{array}$ \\
\hline
\end{tabular}


Continued table

\begin{tabular}{|c|c|c|}
\hline Items & Comments & Suggestion \\
\hline $\begin{array}{l}\text { Part C : Input } \\
\text { Device Risk } \\
\text { Factor } \\
\text { C1 - Keyboard } \\
\text { C2 - Mouse } \\
\text { Positioned } \\
\text { C3 - Mouse Size }\end{array}$ & $\begin{array}{l}\text { - Good } \\
\text { - C1 need have distance } \\
\text { - C1 why don't have score for } \\
\text { keyboard position in line with } \\
\text { elbow } \\
\text { - CI difficult to determine the angle } \\
\text { of wrist } \\
\text { - Illustration too small } \\
\text { - C1- only have too high or too low } \\
\text { keyboard positioned } \\
\text { - C1 - sentence not clear/ confusing } \\
\text { - C1 - combine both side, it is } \\
\text { related } \\
\text { - C2 need add instruction - only for } \\
\text { one hand } \\
\text { - C2 confusing }\end{array}$ & $\begin{array}{l}\text { - Need bold the keyword } \\
\text { - Add keyboard for another level } \\
\text { (keyboard position) } \\
\text { - Enlarge the illustration } \\
\text { - C1- added neutral keyboard } \\
\text { positioned (to avoid assessor } \\
\text { confused) } \\
\text { - C1- consisted two evaluated } \\
\text { section. It should be do separately } \\
\text { - C1-Fix the sentence to more } \\
\text { clear. } \\
\text { - C2- need more detailed } \\
\text { explanation } \\
\text { - Just put one side for mouse } \\
\text { position (more easy) - no need } \\
\text { put left and right side }\end{array}$ \\
\hline $\begin{array}{l}\text { Part D: Monitor } \\
\text { Risk Factor } \\
\text { D1 - Angle View } \\
\text { D2 - Distance } \\
\text { View }\end{array}$ & $\begin{array}{l}\text { - Good } \\
\text { - Keyword for that sentence not } \\
\text { clear } \\
\text { - Difficult to assess the neck angular } \\
\text { range for monitor range }\end{array}$ & $\begin{array}{l}\text { - Need bold the keyword } \\
\text { - Add screen brightness factor } \\
\text { - Angle } 15^{\circ} \text { still ok, need make } \\
\text { range from } 0^{\circ}-30^{\circ}\end{array}$ \\
\hline $\begin{array}{l}\text { Part E : } \\
\text { Accessories Risk } \\
\text { Factor } \\
\text { E1 - Telephone } \\
\text { E2-Document } \\
\text { Holder } \\
\text { E3 - Keyboard } \\
\text { Wrist rest } \\
\text { E4- Mouse Wrist } \\
\text { rest }\end{array}$ & $\begin{array}{l}\text { - Good } \\
\text { - The Illustration E2 not clear } \\
\text { (confused) but the sentence clear. } \\
\text { - Dimension too small } \\
\text { - Font and Keyword for that } \\
\text { sentence not clear } \\
\text { - E1 need have distance } \\
\text { - E1 not easy to completed } \\
\text { (illustration too confusing) } \\
\text { - What if: document holder is in } \\
\text { front of monitor but beck flexion is } \\
\text { not }>15^{\circ}\end{array}$ & $\begin{array}{l}\text { - Make dimension more bigger } \\
\text { - Need bold the keyword } \\
\text { - Illustration need more specific } \\
\text { - Give instruction for E2 more } \\
\text { clear } \\
\text { - E1- consisted two evaluated } \\
\text { section. It should be do separately }\end{array}$ \\
\hline $\begin{array}{l}\text { Part F: } \\
\text { Office } \\
\text { Environment Risk } \\
\text { Factor } \\
\text { F1 - Lighting } \\
\text { F2 - Temperature } \\
\text { F3 - Noise }\end{array}$ & $\begin{array}{l}\text { - Scoring for item F1 confusing } \\
\text { - Font too small } \\
\text { - Too much types of office } \\
\text { (confused). } \\
\text { - Not colourful } \\
\text { - This part make confused } \\
\text { - Keyword for that sentence not } \\
\text { clear } \\
\text { - Range of score limited (rigid) } \\
\text { - The recommended temperature } \\
\text { rating may not be appropriate }\end{array}$ & $\begin{array}{l}\text { - Make it more colourful like other } \\
\text { part } \\
\text { - Need enlarge the font size } \\
\text { - Need bold the keyword } \\
\text { - Need to add more range } \\
\text { - Better if there is no double range. } \\
\text { - Suitable temperature at } 20^{\circ} \mathrm{C}- \\
30^{\circ} \mathrm{C} \\
\text { - Make more research for lighting } \\
\text { rating } \\
\text { - Better if part for F1, F2, and F3 } \\
\text { separated for easy to understand } \\
\text { but still in office environment } \\
\text { part }\end{array}$ \\
\hline
\end{tabular}




\section{Discussion}

\subsection{Feedback Survey on the Usability of the OFFERA method}

All the participants $(\mathrm{N}=44)$ gave their feedback on the usability of the OFFERA Tool (Table 1 and Figure 1) is the results indicated that the OFFERA tool is easy to use (mean $4.48 \pm 0.698$ ) and quick to use (mean $4.48 \pm 0.821$ ) with the percentages of $93 \%$ (agree) and $91 \%$ (strongly agree) respectively. The observers found that, the OFFERA method was easy to understand and suitable for evaluating ergonomic risks. Besides that, they stated that the OFFERA method will be very handy for determining office ergonomic factors. The observations also showed that the prototype tool is applicable in workplace assessment (mean $4.52 \pm 0.549$ ), and a wide range of jobs (mean $4.02 \pm 0.952$ ) with percentages of 93\% (agree) and $80 \%$ (strongly agree) respectively. This is because the observers found that the OFFERA tool useful for assessing the workplace environment. Other than that, observer found, this prototype is a good ensure the person always in a good posture that can be avoided from the hazard.

The feedback from the observers during the training session on the score for the item 'clear instruction and easy to understand' (mean $3.93 \pm 1.149$ ) and 'clear wording and easy to understand (mean $3.91 \pm 1.096$ ) showed that the assessment was not clear. In addition, the percentage of the observers who responded either 'agree' or 'strongly agree' was less than $80 \%$. The observers found that the font used was too small and hence made it difficult for them to read the instructions. The pictures or illustrations in the OFFERA tool ware also said to be unclear based on the relatively low score (mean $3.73 \pm 1.128$ ) as the percentage of the observers who either 'strongly agree' or 'agree' was only $66 \%$. This is because the observers found it difficult to observe and define the range of angular values for monitors angle, keyboard, telephone and desk depth/ width. Besides that, the observers found it difficult to observe and define the range of angular values during the assessment of items related to neck posture. In fact, other studies revealed that it is difficult for observers to determine the worker's posture angle based on observation only $[8,15]$

A study by Dartt et al., [18] found that the assessment of wrist posture to be more difficult to assess compared to other joints because of its dynamic posture. In the OFFERA tool, the participants confirmed that it was easy to understand the scoring system (mean $4.59 \pm 0.622$ ), score for each items (mean $4.50 \pm 0.792$ ), the final score (mean $4.68 \pm$ 0.639 ), and the action level (mean $4.52 \pm 0.549$ ) are useful. This is because the observers concluded that based on the final score of the tool, it was easy to obtain the final score and determine the action level. The feedback from the practitioners on the score for items such as 'cost effective' (mean $4.36 \pm 0.685$ ), and 'provide a good basis for intervention proposal' (mean $4.41 \pm 0.583$ ) indicated that the tool is also practical and useful for the workplace.

\subsection{General comments and suggestions for the OFFERA method}

Most of the practitioner commented that the wording or font used was too small and made it difficult to read the sentences. Meanwhile, the percentage of observers who agree and strongly agree with the 'wording clear and understand' (mean $3.91 \pm 1.096$ ) only $73 \%$ (below 80\%). This shows that their responses in the questionnaire are also reflected in their comments. Other than that, the observers also suggested that the illustrations and the dimension for each diagram should be enlarged to make them clearer and more understandable. In terms of reliability, the observers mentioned that it was difficult to assess the monitor angle $(\mathrm{K}=0.58)$ because the illustration of the angle was not clear. They also commented that it was difficult and confusing to assess the neck posture. According to other studies, the observers found it difficult to observe and determine the angle during the 
assessment of body posture [8]. This is because only $66 \%$ of the observers agree and strongly agree that the illustrations are clear and easy to understand. Other than that, during the training session, the observers stated that it was difficult and confusing to assess the keyboard position item. This happened because the illustrations of that item were not clear. It was difficult to determine whether the wrist posture was below or above especially for typing job. However, the questionnaire revealed that the observers agree $(43 \%)$ and strongly agree $(55 \%)$ that the tool is 'applicable to workplace assessment'. The observer found that the OFFERA method can be used for a wide range of office work (useful for assessing the workplace environment). Besides that, the observer found that the OFFERA method is a good way to ensure that office workers maintain a good posture at work.

\subsection{Specific comment and suggestion for OFFERA method}

Table 4 shows that most of the observers commented that the font and dimension for all items were too small and made it difficult for them to read. In this case, they suggested enlarging the font size and dimension for the items. Besides that, some of the observers were confused with item A4 (armrest) about how to differentiate between the hands placed on the desk with a chair and have an armrest but not used it. The observers suggested that a high score should for the risk factor "armrest but not used". Other than that, observers also suggested to put the keywords for each item in bold. It can make the observer more understand and clearer about the sentences. Besides that, the observer stated using the simple words to explain each items will make the assessment easier because using the word "OR" in each evaluation would confuse the observers. Other than that, the observers found Part A to be good, clear and interesting to assess. Besides that, Dockrell et al., [19] stated that the sitting posture or static posture is easier to assess compared to dynamic postures.

For part B, most of the observers commented about item B2 (desk depth/width). Some of the observers commented that they did not understand how to assess the desk depth/width because they were confused about the range and the illustration of the desk. Therefore, the percentage of agreement for the item 'illustration is clear and easy to understand' was only $66 \%$. Besides that, they opined that a bigger desk would be more comfortable. The observers suggested that a range for B2 should be a provided in a few size and perhaps the dimension of B2 in a range. For B1 (desk height), the observers found that there was no maximum height provided only have a low height and suitable height. Because of that, they suggested adding the range/score for 'a desk too high' at B1.

For Part C (input device), most of the observers commented about item CI (keyboard). They found this item very confusing to assess because they needed to combine two scores in one item. Therefore they suggested that should be a distance between the score and that clearer instruction should be provided. Besides that, it was difficult for them to determine the wrist angle for item $\mathrm{C} 1$ because the illustration was too small. In addition, the observers had difficulty in determining the position of the wrist posture and the angle when assessing the wrist posture during typing activity. Besides that, another researcher also found that it is was difficult for an observer to assess whether the wrist angle was $15^{\circ}$ or $20^{\circ}$ from its neutral position during task performance [20]. Other than that, assessing the wrist posture for typing and clicking activities was more difficult to assess compared to other joints because it is dynamic posture (repetitive movement occur) [18]. The sentence for the item was also not clear so the keywords need to be bold.

For Part D (monitor), the observers found it too difficult to assess the range of angles of the neck for monitor range. Because of that, they suggested that a suitable angle range for the neck be adjusted to $0^{\circ}-30^{\circ}$ because an angle of $15^{\circ}$ was still acceptable for them. According to David et al., [15], observers found it difficult to determine the worker's posture angle based on observation only. Besides that, Li and Buckle [20] found the 
observation easier to assess when using the terms such as 'bend up' (extension) and 'bend down' (flexion) compared to use of angular angle. Other than that, they suggested the use of 'bold' keywords in the sentence to avoid observer confused during assess the tool.

In Part E (accessories), the observers found it difficult to assess the telephone and document holder. They stated that items (telephone) need to be separated or have a distance because there was a combined score. Besides that, they found it hard to use the tool because the illustrations were too confusing. This happened, because the evaluation on the telephone consists of two sections. The observers suggested separating the scores. Besides that, the illustrations of the telephone and document holder need to be more specific and clear. For the document holder, the illustration was not very clear but the description was easy to understand. The observers asked about neck flexion below $15^{\circ}$ but the document holder is in front of the monitor. They also suggested the need to have scores for that situation.

For part F (environment), the observers found that the range of the scores for lighting and noise was limited (rigid) and made assessment difficult. The observers suggested that the range should be extended but a double range should be employed because it can be confusing. Besides that, the observers suggested that items F1, F2, and F3 should be separated but still in the office environment part. It makes the observers easier to assess.

\section{Conclusion}

To conclude, from the feedback pertaining to the usability of the OFFERA method gathered via questionnaires, all participants agreed that the OFFERA method is both userfriendly and cost-effective. The observers found that, the prototype was suitable to evaluating ergonomic risks and easy to understand. Besides that, they stated that the tool will be very handy to determining the office ergonomic factors. The observations show that the OFFERA method is applicable in workplace assessments and in a wide range of jobs. The observers also noted that, it can be useful for assessing the workplace environment. In addition, the participants confirmed that the OFFERA method had scoring systems, scores for each item, final score, and action levels which were clear and easy to comprehend. However, the observers lamented that the font use was too small and thus made it difficult to read the instructions. The picture or illustrations in the OFFERA method were also recorded as unclear based on the relatively low score for 18 items. This is because the observers found it difficult to observe and define the ranges of angular values for monitors angle, keyboards, telephones, and desks depth/width. After the usability test, the OFFERA method has been revised. Besides that, OFFERA tool needs to be reassessed in terms of usability in future studies.

This research is funded by the Ministry of Higher Education of Malaysia (MOHE) and Universiti Tun Hussein Onn Malaysia (UTHM) under the Fundamental Research Grant Scheme (FRGS, Vot 1495)

\section{References}

1. B.P. Bernard, Musculoskeletal disorders and workplace factors: critical review of epidemiologic evidence for work-related musculoskeletal disorders of the neck, upper extremity, and low back. National Institute for Occupational Safety and Health (NIOSH). Cincinnati, OH (1997). 
2. M.N.A. Rahman, M.R.A. Rani, and J.M. Rohani, Investigation of work-related musculoskeletal disorders in wall plastering jobs within the construction industry. Work, 43(4), 507-514 (2012).

3. M.N.A. Rahman, F.A. Aziz, and R.M. Yusuff, Survey of body part symptoms among workers in a car tyre service centre. Journal of human ergology, 39(1), 53-56 (2010).

4. M.N.A. Rahman, H.R. Haq, M.F. Hassan, M.A. Arifin, M.Z. Yunos, S.A. Bakar, and S. Adzila, Musculoskeletal discomfort among workers in mould making manufacturing industry. ARPN Journal of Engineering and Applied Sciences, 10(15), 6269-6273 (2015).

5. M. Sonne, D. L. Villalta, and D. M. Andrews, Development and evaluation of an office ergonomic risk checklist: ROSA-Rapid office strain assessment. Applied ergonomics, 43, 98-108 (2012).

6. M. Robertson, B. C. Amick, K. DeRango, T. Rooney, L. Bazzani, R. Harrist, A. Moore, The effects of an office ergonomics training and chair intervention on worker knowledge, behavior and musculoskeletal risk. Applied Ergonomics, 40(1), 124-135 (2009)

7. J. Village, D. Rempel, K. Teschke, Musculoskeletal disorders of the upper extremity associated with computer work: a systematic review. Occup. Ergon. 5, 205-218 (2005).

8. M.N.A. Rahman, M.R.A. Rani, J.M. Rohani, WERA: an observational tool develop to investigate the physical risk factor associated with WMSDs. J. Hum. Ergol, 40,19-36 (2011)

9. A. Loghmani, P. Golshiri, A. Zamani, M. Kheirmand, N. Jafari, Musculoskeletal symptoms and job satisfaction among office-workers: A Cross-sectional study from Iran. Acta Medica Academica, 42, 46-54 (2013).

10. M.N.A. Rahman, N.H. Zakaria, I. Masood, S. Adzila, and N.F. Nasir, Risk Assessment for Assessing the Subjective Occupant Seating Discomfort related Office Works. International Information Institute (Tokyo). Information, 19(7B), 3025-3030 (2016).

11. L. Eyal, J. Ribak, Y. Badihi, Remote online ergonomic assessment in the office environment as compared to face-to-face ergonomic assessment. Work: A Journal of Prevention, Assessment and Rehabilition, 41,516-523 (2012)

12. L. McAtamney, and E.N. Corlett, RULA: A survey method for investigation of workrelated upper limb disorders. Applied Ergonomics, 24(2), 91 - 99 (1993)

13. S. Hignett, \& L. McAtamney, Rapid entire body assessment (REBA). Applied ergonomics, 31(2), 201-205 (2000).

14. Occupation Safety \& Health Administration, Computer Workstation e-Tool Checlist, United State Department of Labor (2003).. Retrived from https://www.osha.gov.

15. G. David, V. Woods, G. Li, P. Buckle, he development of the Quick Exposure Check (QEC) for assessing exposure to risk factors for work-related musculoskeletal disorders. Applied Ergonomics, 39(1), 57-69 (2008).

16. J.G. Ferreira, M. Hunter, L.M. Birtles, \& D. Riley, Development of an assessment tool for repetitive tasks of the upper limbs (ART) (2009). Derbyshire: Health and Safety Executive.

17. J.S. Dumas, and M.C. Salzman, Usability assessment methods. Reviews of human factors and ergonomics, 2(1), 109-140 (2006).

18. A. Dartt, J. Rosecrance, F. Gerr, P. Chen, D. Anton, L. Merlino, Reliability of assessing upper limb postures among workers performing manufacturing tasks. Applied Ergonomics, 40(3), 371-378 (2009). 
19. S. Dockrell, E. O'Grady, K. Bennett, C. Mullarkey, R. Mc Connell, R. Ruddy, C. Flannery, An investigation of the reliability of Rapid Upper Limb Assessment (RULA) as a method of assessment of children's computing posture. Applied Ergonomics, 43(3), 632-636 (2012).

20. G. Li, \& P. Buckle, Current techniques for assessing physical exposure to work-related musculoskeletal risk, with emphasis on posture-based methods. Ergonomics, 42(5):674-695 (1999). 